\title{
La simbiosis entre ética y filosofía de la historia, o el rostro jánico de la moral kantiana ${ }^{1}$
}

\author{
ROBERTO RODRIGGUEZ ARAMAYO \\ Instituto de Filosofia del CSIC
}

Contra lo que suele pensarse, la ética y la filosofía de la historia no suponen dos compartimentos estancos dentro del criticismo, sino que se hallan estrechamente relacionadas, a modo de vasos comunicantes, al igual que lo están las respuestas dadas a la segunda y tercera de sus célebres preguntas. A fin de cuentas, la moral kantiana no sabe renunciar a una suerte de imperativo $e$ pidológico que cumplimente cabalmente al categórico. El hombre no puedc prescindir de la esperanza, pues ha de creer en el éxito de sus proyectos, y esa será la función ejercida por ideas tales como "Dios", «Naturaleza» o "Destino»: proporcionar el talante o estado anímico adecuado para no tomar nuestros afanes morales por tareas quiméricas e imposibles, dotarnos de la confianza necesaria para sortear cualquier linde que pretenda cercar nuestra libertad y obstaculizar la paulatina remodelación nouménica del mundo fenoménico. De ahí el precepto kantiano de que «si debo, puedo».

[...] desde luego, con una certeza que no basta para pronosticar (teóricamente) el futuro, pero sí resulta suficiente desde un punto de vista práctico para convertir en un deber el hecho de trabajar en pro de tal meta y no tenerla por una mera quimera (KANT, La paz perpetua, Ak., VIII, 368).

\section{La paloma y la isla}

En el prólogo a la primera edición de la Crítica de la razón pura, su autor se disculpa ante los lectores por sentirse obligado a prescindir de unos ejemplos e ilustraciones que hubieran alargado demasiado la obra y salpicaban el primer esbozo. ${ }^{2}$ Afortunadamente, no todas las ilustraciones fueron suprimidas y esa circunstancia nos permite comenzar este trabajo glosando un par de metáforas debidas a la pluma del filósofo de Königsberg. Ambas pertenecen a la primera Crítica y una cobró cierta fama entre nosotros, al ser utilizada por Juan de Mairena en sus clases de Retórica. Nos referimos, claro está, a esa paloma que, al sentir la resistencia del aire en sus alas, podría imaginar que volaría mucho mejor aún en un espacio vacío. «Así ilustra Kant —escribe Antonio Macha- 
do- su argumento más decisivo contra la metafísica dogmática, que pretende elevarse a lo absoluto por el vuelo imposible del intelecto discursivo en un vacío de intuiciones. $)^{3}$ Es verdad que uno de los principales objetivos del criticismo kantiano consistía en poner bridas a las desbocadas pretensiones epistemológicas de la metafísica dogmática, constatando que la intuición no puede ser sino sensible, pero no es menos cierto que la metáfora de la paloma no fue forjada con esa única intención. De hecho, el texto en cuestión continúa diciendo que "de esa misma forma abandonó Platón el mundo de los sentidos, por imponer límites tan estrechos al entendimiento, y se aventuró allende los mismos en el espacio vacío del entendimiento puro con las alas de las ideas". ${ }^{4}$ Semejante audacia resulta envidiable para Kant. Su sistema adoptará esas alas eidéticas ansiadas por Platón, asignándoles una función teorética y atra de índole práctico. Para la filosofía transcendental resulta obvio que no nos es posible aumentar nuestro caudal de conocimiento con meras ideas, tal y como un comerciante no es capaz de incrementar su patrimonio añadiendo algunos ceros al dinero con que cuenta realmente. ${ }^{5}$ Ahora bien, no hemos de olvidar que, pese a todo, el cero articula todo el sistema métrico decimal; de igual modo, las ideas regulan todo nuestro proceso cognoscitivo, aun cuando ellas mismas no representen ningún objeto determinado. ${ }^{6}$

El otro símil al que aludíamos viene a cumplimentar cabalmente todo este planteamiento kantiano. Se trata de aquel donde se compara el ámbito de lo cognoscible con una ínsula cercada por mares procelosos. «Ese territorio -escribe Kant- es una isla encerrada por la propia naturaleza entre lindes inalterables, que se ve rodeada por un océano ancho y borrascoso, donde unos cuantos icebergs envueltos por la bruma aparentan nuevas tierras y engañan continuamente al navegante con la vana ilusión de realizar algún descubrimiento, embarcándole en aventuras que nunca es capaz de abandonar, pero tampoco puede llevar a cabo jamás.» ${ }^{7}$ La metáfora en cuestión admite una doble lectura. Por una parte, prescribe a los epistemólogos la necesidad de ceñir su especulación al terreno firme que se ve acotado por la barrera infranqueable de la sensibilidad, habida cuenta de que nuestro entendimiento discursivo no puede llegar a conocer nada en absoluto sin contar con la intuición sensible. Pero con ello no se agota, ni muchísimo menos, todo su potencial significativo. Este símil cartográlico modifica radicalmente su significado si lo situamos bajo el prisma de la moral. Y es que, mientras el conocimiento especulativo se ve anclado a la intuición sensible y no puede abandonar las orillas de su seguro islote, yendo en pos de ilusiones fantasmagóricas, sin naufragar irremisiblemente, el universo ético, en cambio, no puede ser explorado sino merced al vuelo emprendido por las ideas de la razón. 
Ciertas cosas - asevera Kant- sólo se dejan conocer a través de la razón y no por medio de la experiencia; esto es así siempre que no se desea saber cómo es esto o aquello, sino cómo debe o ha de ser. De ahí las ideas de Platón. ${ }^{8}$

\section{El papel de las ideas}

¿Qué es una «idea» para Kant? Pues aquello que expresa «una perfección no encontrada aún en la experiencia». ${ }^{9}$ Las ideas son "conceptos de una perfección a la que cabe acercarse siempre, pero nunca alcanzarla completamente». ${ }^{10} \mathrm{El}$ ejemplo predilecto de nuestro autor es el de una república de corte platónico. El razonamiento kantiano concluye que, «aunque no llegue a tener lugar nunca, la idea que propone ese maximum como arquetipo resulta plenamente adecuada para aproximar siempre un poco más la constitución jurídica de los hombres a la mayor perfección posible conforme a ese modelo. Pues nadie puede ni debe determinar cuál sea la cota donde la humanidad tiene que detenerse o cuán grande haya de ser el abismo que medie entre la idea y su realización, habida cuenta de que la libertad es capaz de sortear cualquier límite prefijado de antemanos. ${ }^{11}$

El gran mérito de Platón reside, justamente, en haber situado los principios de la moral en el ámbito de las ideas, ya que sólo tales ideas posibilitan la experiencia del bien, aun cuando no puedan verse plenamente manifestadas en la propia experiencia. "En efecto, si la experiencia nos suministra las reglas y es la fuente de la verdad en lo que atañe a la naturaleza, esa misma experiencia es (por desgracia) madre de la ilusión en lo referente a las leyes morales, resultando por ello harto reprobable el tomar las leyes relativas a lo que se debe hacer de aquello que se hace o bien limitarlas en virtud de esto ûltimo. $\gg^{12}$ Ante los ojos de Kant,

[...] no cabe nada más pernicioso e indigno de un filósofo que la plebeya apelación a una presunta experiencia contradictoria, la cual no hubiera tenido lugar de haber existido a tiempo disposiciones conforme a ideas y de no existir en su lugar burdos conceptos, sacados precisamente de la experiencia, que hicieran fracasar toda buena intención. ${ }^{13}$

\section{La ficción heuristica del «como si»}

En este orden de cosas, nos encontramos con la idea del contrato social, la cual es «una mera idea de la razón que tiene, sin embargo, su indudable realidad (práctica), a saber, la de obligar a todo legislador a que dicte sus leyes como si éstas pudieran haber emanado de la voluntad unida de todo un pueblo, pues ahí se halla la piedra de toque de la legitimidad de toda ley pública». ${ }^{14}$ Todo cuanto contravenga al espíritu del contrato so- 
cial, lo que resulte incompatible con esta idea, será contrario al derecho y habría de ser expatriado automáticamente del orbe jurídico. Tal es el mecanismo de una noción muy querida para Kant, la ficción heurística del como si, la cual presenta - como es habitual dentro del sistema crítico- una doble rentabilidad.

Desde un punto de vista teórico, "considerar las cosas del mundo como si recibieran su existencia de una inteligencia suprema» nos permite recurrir a un expediente de carácter teleológico allí donde no se muestre solvente la explicación mecanicista, tal y como le acontece por ejemplo al estudioso de la naturaleza orgánica..$^{15}$ La invocación kantiana del teleologismo constituye, por lo tanto, el perfecto antagonista de aquel "asilo de la ignorancia» del que nos hablara Spinoza en el Apéndice al primer libro de su Ética, habida cuenta de que la teleología es utilizada por el criticismo para orientar la tarea del investigador cuya pretensión sea desentrañar los misterios de la naturaleza orgánica. Para la filosofía transcendental semejante investigación sólo puede proseguir y arribar a puertos cada vez más lejanos gracias al auxilio del juicio reflexionante.

En ocasiones - confiesa Kant en uno de sus borradores nunca dados a la imprenta- también he probado a navegar por ese golfo bajo la suposición de un ciego mecanicismo natural, y creía descubrir una travesía hacia un concepto de naturaleza sin arte; mas la razón siempre quedaba varada en la playa y preferí aventurarme en el inconmensurable océano de las ideas. ${ }^{\text {it }}$

\section{El «Kepler» del mundo histórico}

El Kant filósofo de la historia seguirá idéntico razonamiento. En su "Idea» para una historia universal nuestro autor descarta la hipótesis del ciego azar y escoge la ficción de una secreta sabiduría que rige los destinos del devenir histórico. ${ }^{17} \mathrm{El}$ espíritu de dicha elección es «descubrir en el absurdo decurso de las cosas humanas una intención de la Naturale$z a "{ }^{18}$ que nos ayude a "cobrar ánimo en medio de tantas penalidades y nos invite a no desaprovechar la baza del autoperfeccionamienton. ${ }^{19}$ Tal es la tarea desempeñada por ese "plan oculto de la Naturaleza» cuyo estrecho parentesco con "la mano invisible» de Adam Smith resulta sencillamente incuestionable. $\mathrm{Y}$ es que, como muy bien explica Collingwood, "desde el punto de vista de Kant era tan legítimo hablar de un plan de la Naturaleza revelado en los fenómenos estudiados por el historiador como hablar de leyes de la Naturaleza reveladas en los estudiados por el científico. Lo que las leyes de la Naturaleza son para el hombre de ciencia, son los planes de la Naturaleza para el historiador. Cuando el hombre de ciencia se describe a sí mismo como descubriendo leyes de la Naturaleza, no quiere decir que haya un legislador llamado "Naturaleza"; 
lo que quiere decir es que los fenómenos muestran una regularidad y un orden que no sólo puede, sino que debe ser descrito mediante alguna metáfora de este tipo. De manera semejante, cuando el historiador habla de un plan de la Naturaleza que se desarrolla en la historia, no quiere decir que exista una mente real llamada "Naturaleza" que elabore conscientemente un plan que ha de cumplirse en la historia, quiere decir que la historia procede como si existiera tal mente". ${ }^{20} \mathrm{El}$ propio Collingwood, suscribiendo en este punto las premisas del planteamiento kantiano, afirma rotundamente que «no nos es posible pensar en la historia sin emplear metáforas teleológicas».21

Ahora bien, con la constatación de semejante hilo conductor Kant alberga una pretensión que él considera modesta, cual es oficiar como una especie de Kepler del mundo histórico, a la espera de que se produzca el advenimiento del Newton correspondiente. A su modo de ver, el universo ético cuenta ya con su Newton particular, encarnado en la figura de J.-J. Rousseau, ${ }^{22}$ pero la biología y la historia corren peor suerte. La primera no puede ni tan siquiera confiar en que algún día se presente un "Newton de la hierba", según sentencia la tercera Crítica $^{23}$ en un pasaje que devino bastante célebre, ${ }^{24}$ en tanto que la segunda habrá de seguir esperándolo indefinidamente.

Vamos a ver si logramos encontrar un hilo conductor para diseñar una historia semejante, dejando en manos de la Naturaleza el engendrar al hombre que habrá de componerla más tarde sobre esa base; de la misma manera que produjo un Kepler, el cual sometió de forma inesperada las formas excéntricas de los planetas a leyes determinadas y, posteriormente, a un Newton que explicó esas leyes mediante una causa universal de la Naturaleza. ${ }^{25}$

\section{La «asintota»: algo más que una metáfora}

Para el filósofo de Königsberg, la biología escapa del cedazo matemático al que Newton supo someter a la física, logrando que los planetas trazaran en sus trayectorias figuras geométricas. Desde luego, es una lástima que así sea; pero bueno, al fin y a la postre, no está en juego sino un mero interés teórico-especulativo. En el caso de la historia, sin embargo, Kant no puede resignarse tan fácilmente, al quedar comprometida la praxis.

Esta diferencia dista mucho de ser baladí para el padre del criticismo, ya que, mientras el interés especulativo nos conduce a la forja de hipótesis, el práctico impone acuñar postulados. ${ }^{26}$ Incluso el estatuto de Dios mismo dependerá del interés de la razón que se ventile. La exigencia especulativa sólo nos descubre la hipótesis de un Entendimiento Artista, como concepto regulativo que nos es útil a la hora de comprender la realidad. El interés práctico, por el contrario, nos impone la postula- 
ción de un Creador moral; ya veremos para qué. De ahí que Kant se autoerija en el Kepler de turno y decida recurrir a la geometría, para resolver una grave aporía que fuera planteada por el estoicismo. Nos referimos al aparentemente injusto sacrificio de los individuos en aras del progreso de la especie. En su polémica con Herder, Kant alumbrará la bella imagen del decurso asintótico, queriendo disolver así uno de los mayores problemas al que ha de hacer frente cualquier filosofía de la historia. La solución que nos brinda es la siguiente:

[...] si la especie supone el conjunto de una serie de generaciones que se extiende hasta el infinito y se acepta que tal serie se aproxima incesantemente a la línea de su destino, entonces no resulta contradictorio sostener que esta línea del destino es asintótica a cada uno de los puntos de la línea generacional y coincide con ésta en el todo. Es competencia del matemático aclarar esta metáfora; la tarea del filósofo consiste en afirmar que el destino del género humano en su conjunto es un progresar ininternumpido.27

\section{El horizonte de la utopia ucrónica}

La imagen del decurso asintótico se convierte así en un axioma central del pensamiento práctico de Kant. La filosofía kantiana de la historia sólo cobra sentido adoptando esa premisa, que pierde su carácter de metáfora para cobrar el rango de postulado. El filósofo no puede afrontar la historia sino como el escenario donde se interpreta un determinado guión (el suyo propio), merced al cual el género humano se acerca gradualmente hacia un destino que, por lo demás, ha de ser inalcanzable. El devenir histórico es un viaje sin término, una eterna singladura en pos del Destino, entendiendo éste como un incesante despliegue de aquellas disposiciones naturales que se hallan orientadas a un mejor uso de la razón. La humanidad, al querer aproximarse a ese horizonte utópi$c o$, progresa cada vez más, pero este progreso nunca se verá consumado por definición, puesto que se trata de una meta ucrónica o, lo que viene a ser lo mismo, asintótica.

Siempre será posible acercarse un poco más a ese horizonte asintótico que configuran los utopemas del momento, siendo aquí donde se verifica una perfecta simbiosis entre la ética y la filosofía de la historia kantianas. Este aserto puede comprobarse, por ejemplo, compulsando lo que Kant comenta en relación con las utopías clásicas, como la Atlantida de Platón o la Utopía de Moro;

[...] esperar que un constructo político como los reseñados llegue a materializarse algún día - por remoto que sea- es un dulce sueño, pero aproximarse constantemente a ese horizonte utópico no sólo es algo imaginable, sino que, en cuanto pueda compadecerse con la ley moral, constituye un deber, ${ }^{28}$ 


\section{El «reino de Dios en la tierra»}

La persecución de tales ideales es declarada por el criticismo como un deber, aun cuando su plena consecución resulte imposible desde un principio. No importa que nunca logremos llegar hasta el extremo del arco iris, lo que cuenta es el camino recorrido en pos de semejante objetivo, los territorios que se vayan conquistando y colonizando a lo largo de tan singular periplo. Estos nuevos dominios irán conformando paulatinamente lo que Kant da en llamar el reino de Dios en la tierra.

Dicho reino es definido alguna vez por Kant como «el destino final del ser humano", pero eso sí, como "un destino que no podrá ser alcanzado por el individuo, sino por la totalidad $\gg{ }^{29}$ Sólo el género humano en su conjunto puede aspirar a llegar alguna vez hasta la base del arco iris (por seguir utilizando este símil para designar genéricamente al horizonte utópico), algo que resulta imposible para cualquiera de sus miembros. Éstos deben conformarse con avanzar asintóticamente hacia él, a fin de remodelar el mundo fenoménico conforme al nouménico. Después de todo,

[...] el reino de los cielos no es una cuestión topográfica, ya que los hombres pueden forjar cielo e infierno alli donde se hallen. ${ }^{30}$

\section{El «a priori» en la historia}

Desde luego, Kant no se muestra en absoluto partidario de transferir las propias responsabilidades, como muestran algunas páginas de la Crítica de la razón práctica. ${ }^{31}$ De nada vale intentar cobijarse bajo la sombra del determinismo, escudándose tras un sinfín de imponderables y toda suerte de coartadas, para evacuar nuestra responsabilidad. Por ello no resulta extraño que, fiel a esa máxima, proponga «evitar la tentación de responsabilizar por completo al destino, y no perder de vista nuestra propia culpa, por si acaso ésta resultare ser la única causa de todas nuestras calamidades». ${ }^{32}$

El autor de la segunda Crítica mantiene que no nos es posible abjurar de nuestra libertad y que siempre debemos abogar por ella, incluso llegado el caso de que pudiéramos penetrar en la mente de un hombre, de modo que no nos fuese ajeno ni el más insignificante de sus móviles, y conociéramos al mismo tiempo todas aquellas circunstancias externas que operan sobre él, cupiendo así «calcular con seguridad la conducta de un hombre en lo porvenir, como los eclipses de sol y de luna", ${ }^{33} \mathrm{La}$ premisa de la libertad ${ }^{34}$ no deja lugar a los pronósticos y las profecías, pues "nadie puede ni debe determinar cuál haya de ser la última cota donde la humanidad tenga que detenerse, así como cuán profundo sea el 
abismo que reste por salvar entre la idea y su realización, dado que la libertad es capaz de franquear cualquier frontera prefijada»..$^{35}$ Así las cosas, los vaticinios no pueden tener éxito sino cuando es el propio augur quien propicia ese desenlace, cual es el caso de los profetas judíos, de la casta política o del clero, quienes, al tener las riendas de la situación, pueden ostentar con absoluta infalibilidad el don que le fuese conferido a Casandra. En la historia no disponemos de mecanismos que nos permitan predecir los acontecimientos tal y como se predice un eclipse solar o lunar; por eso, cuando Kant se pregunta: ¿cómo es posible una historia a priori?, responde con toda premura:

Muy sencillo, cuando es el propio adivino quien causa y prepara los acontecimientos que presagia. ${ }^{36}$

\section{El «hacerse digno de...»}

Lejos de suscribir la tesis leibniziana de una armonia preestablecida entre los reinos de la Naturaleza y de la Gracia, Kant cree que dicha conjunción entre naturaleza y libertad ha de ser conquistada por nosotros. Semejante armonía constituye una mera potencialidad y la tarea de su actualización se halla en manos del hombre, quien cuenta con las ideas de la razón práctica para llevar a cabo esa empresa. Pues el quiliasmo implícito en la filosofia transcendental se caracteriza, precisamente, porque su advenimiento sólo puede verse propiciado por la propia idea del quiliasmo mismo. ${ }^{37}$

La moral kantiana es bien consciente de que "las cosas que son regalo de la suerte no pueden entrar en la cuenta del propio mérito» ${ }^{38}$ y por eso se define como la doctrina que nos enseña, no cómo hemos de hacernos felices, sino que nos instruye sobre cómo debemos llegar a ser dignos de la felicidad ${ }^{39}$ Para el criticismo, «el fin último de la Naturaleza es la mayor perfección y felicidad de los hombres en la medida en que ellos mismos sean sus artífices", ${ }^{40}$ en tanto que se hagan acreedores de tal dicha y perfeccionamiento. Según Kant, el hombre debe hacerse merecedor de todo cuanto disfruta ( $y$ por eso - dicho sea de paso- se muestra contrario a cualquier tipo de herencia), ${ }^{41}$ de modo que ha de ir abriéndose camino "para hacerse digno, por medio de su comportamiento, de la vida y del bienestar» ${ }^{42}$ Otra cosa es que, para llevar a cabo esa singladura, necesite alimentarse con la esperanza, cuyo papel en el terreno de la praxis es asimilado nada menos que al desempeñado por el saber dentro del plano especulativo. Conforme a lo que se afirma hacia el final de la primera Critica, la esperanza cumpliría en el terreno de lo práctico, y con respecto a la ley moral, idénticas funciones a las desarrolladas por el saber y la ley natural en el orden del conocimiento teórico de las cosas. ${ }^{43}$ Este aserto conlleva el planteamiento de una gruesa para- 
doja ${ }^{44}$ puesto que si, por una parte, el "hacerse digno" es declarado conditio sine qua non de la esperanza, tampoco deja de reconocerse que, a su vez, ésta resulta de todo punto insoslayable para fomentar esa precondición sin la cual no cabe albergar una esperanza legítima. ${ }^{45}$ Pero esto es algo sobre lo que volveremos un poco más adelante; de momento sólo nos interesa reparar en que, de acuerdo con la filosofía kantiana,

[...] el hombre ha de proceder como si todo dependiera de él, y sólo bajo esta condición puede esperar que una sabiduría superior concederá la consumación a sus bienintencionados esfuerzos. ${ }^{46}$

\section{Naturaleza, providencia y destino; tres apodos para la esperanza}

Así pues, esta "sabiduría superior», que acabaría por coronar con el éxito nuestros merecidos afanes, no viene a representar sino la confianza del propio sujeto agente, una suerte de talante o estado anímico determinado. Resulta imprescindible creer en la consecución de nuestros propósitos, a fin de no desistir en el intento. Kant lo expresa muy bien con el ejemplo del comerciante, el cual, a la hora de acometer sus empresas, no sólo precisa figurarse que va a ganar algo con ello, sino que, ante todo, debe creerlo, ya que la mera opinión se muestra tan incierta como insuficiente para ese tipo de actividades ${ }^{47}$ "al comerciante, para emprender un negocio, no le basta con opinar que podría ganar algo con ello, sino que necesita creerlo, esto es, que su opinión resulte suficiente para emprender lo incierto». ${ }^{48}$

Esta convicción práctica o fe moral de la razón, que puede llegar a ganar al saber en firmeza y seguridad, ${ }^{49}$ es una creencia que no prescribe nada salvo «cumplir con el deber con arreglo a la propia capacidad y esperar sin certidumbre un complemento a tal esfuerzo".50 De ahí que Kant no encuentre dificultad alguna en ampliar el célebre Deus sive $\mathrm{Na}$ tura proclamado por Spinoza, extendiendo la ecuación hasta el fatum estoico. ${ }^{51}$ En el ensayo sobre La paz perpetua se identifican los términos de "naturaleza", "destino" y "providencia", ${ }^{52}$ pues los tres vienen a cumplir una misma función; en realidad todos ellos no son sino pseudónimos de la única debilidad que cabe imputar a la tan ecuánime como insobornable razón ilustrada, cuyo faible no es otro que la esperanza:

[...] la balanza de la razón no es absolutamente imparcial y uno de sus brazos -el que porta la inscripción esperanza de futuro - cuenta con una ventaja mecánica merced a la cual aquellas razones, aun livianas, que caen en su platillo, hacen alzarse en el otro especulaciones de mayor peso específico; esta es la única inexactitud que no puedo, ni tampoco quiero, eliminar. ${ }^{53}$ 


\section{«Debo, luego puedo»}

Al entender de Kant, «no es preciso creer que existe un Dios, sino que basta con hacerse una idea de un ser tal cuyo poderío no tenga límites en cuanto a la libertad del hombre y su destino». ${ }^{54}$ Dios es una mera idea de la razón; $; 5$ no se trata de "un ser exterior a mí, sino de un pensamiento dentro de mí. Dios es la razón ético-práctica autolegisladora ${ }^{56}$ -se afirma con toda rotundidad en el opus postumum.

Esa es la razón de que todo cuanto se debe hacer sea posible por definición. ${ }^{57}$ El hombre ha de creer que puede realizar cuanto su elpidológica razón le proponga como deber. No es otra la quintaesencia de la libertad. ${ }^{58}$ Ésta permanecería desconocida, si el hombre no la descubriera en su interior merced a la ley moral, al cobrar consciencia de que, si debe, puede. ${ }^{59}$ «El hombre juzga que puede realizar algo, justamente por ser consciente de que debe hacerlon; 60 o lo que viene a ser lo mismo, "es consciente de que puede hacerlo porque debe».61 Cualquier suspicacia en sentido contrario habrá de ser ignorada, en tanto que:

[...] los argumentos empiricos contra el éxito de estas resoluciones tomadas por esperanza son aquí del todo inoperantes; la suposición de que, cuanto basta ahora aún no se ha logrado, sólo por eso tampoco se va a lograr jamás, no autoriza en modo alguno a desistir de propósitos pragmáticos o técnicos (como, por ejemplo, el viajar por el aire con globos aerostáticos), y menos todavía de un propósito moral, pues respecto de este último basta con que no se haya demostrado la imposibilidad de su realización para que constituya un deber..$^{62}$

\section{El imperativo "elpidológico»}

Se ha dicho que la filosofía kantiana de la historia constituye un apéndice de su filosofía moral y que Kant no se hubiera ocupado para nada de la historia, de no ser "por las cuestiones morales que parecía plantear».63 $\mathrm{Y}$ es cierto, sólo que - a mi modo de ver- no se trata de un mero apéndice, sino del corazón que hace palpitar el formalismo ético kantiano. La suposición de un plan de la Naturaleza, de un designio de la Providencia o de un guiño del Destino -que sabrá servirse del antagonismo de la insociable sociabilidad humana e incluso de la guerra para conseguir su propósito- nos proporciona un "principio regulativo", una hipótesis de trabajo cuyo valor no estriba sino en su fecundidad; no se trata de una entidad con existencia propia, sino de un "como si" $" .64$ La idea del mencionado plan representa un concepto heurístico, un hilo conductor que nos provee de «una certeza práctica, de la cual precisamos en cuanto móvil del obrar moral" ${ }^{65}$ ¿Acaso cabe una «teodicea" más antropocéntica y secularizada que la esgrimida por Kant? ${ }^{66}$ 
El imperativo categórico kantiano difícilmente sobrevive sin el auxilio de otro imperativo no menos importante y que podríamos bautizar como elpidológico. Pues, como bien explica $\mathrm{E}$. Weil, esin creer en el progreso moral, el ser finito, cayendo en la desesperación, cesaría de trabajar en el reino de los fines; la fe en un sentido de la historia, en el progreso moral, constituye un deber». ${ }^{67}$ Según el autor de Le Dieu caché, Kant se integra con ello en una tradición, que llegaría hasta Marx, caracterizada por su consciencia de que ael individuo no puede realizar solo, por sus solas fuerzas, ningún valor auténtico, y que siempre necesita un auxilio transindividual sobre cuya existencia debe apostar, pues sólo puede vivir y actuar con la esperanza de un éxito en el que debe creer».68 Tesis que puede verse corroborada en este pasaje de El fin de todas las cosas:

[...] por muy incrédulo que se sea, cuando resulta sencillamente imposible predecir con certeza el exito a base de unos medios escogidos con arreglo a la máxima sabidurfa humana (que, si ha de merecer este nombre, ha de referirse únicamente a la moral) no hay más remedio que creer al modo práctico en una concurrencia de la sabiduria divina en el decurso de la naturaleza. ${ }^{69}$

\section{La cuarta "Critica» de Kant}

Como vemos, la filosofía de la historia y la ética de Kant se dan cita en el intersticio que media entre las respuestas a la segunda y tercera de sus célebres preguntas, la del "qué debo hacer» y la del "qué me cabe esperar». En esa encrucijada de problemás que bordea la frontera entre ambas cuestiones es donde se verifica la simbiosis entre ambas disciplinas. La ética quedaría ciega sin contar con la filosofía de la historia y ésta resultaría vana sin aquélla. Y es que «un albedrío que sabe cómo, pero no hacia dónde tiene que obrar, no puede bastarse». ${ }^{70}$ En opinión del filósofo de Königsberg, el hombre no puede zafarse de semejante curiosidad. Bien pudiera desentenderse y atenerse únicamente al cumplimiento de la ley moral, pero el hecho es que no sabe dejar de preguntarse por el resultado de sus acciones. ${ }^{71}$

La filosofía moral de Kant nos muestra, por lo tanto, una doble faz, sendos perfiles que son como las dos caras de una misma moneda; nos referimos, claro está, al deber y a la esperanza. Aquello que debemos hacer supone algo así como la ratio essendi de cuanto confíamos en conseguir, en tanto que la «elpidologías viene a representar una suerte de ratio cognoscendi del imperativo categórico. ${ }^{72} \mathrm{Sin}$ duda, la ley moral ha de prescindir, para ser tal, de todo móvil y elemento material de determinación, pero las distintas versiones del bien supremo que pueblan el universo kantiano de la esperanza o utopía ucrónica dotan de sentido a su ética sin conculcar ese precepto, ${ }^{73}$ a la vez que proporcionan una con- 
dición de posibilidad al constructo utópico anhelado. De tal forma que, "por más dudas que de la historia quepa extraer contra mis esperanzas -dudas que, si fueran probatorias, podrían inducirme a desistir de un trabajo aparentemente baldío-, mientras eso no pueda probarse con absoluta certeza, me asiste pese a todo la posibilidad de no trocar el deber por la regla de prudencia consistente en no dedicarse a lo impracticable». ${ }^{74}$ La moral kantiana no resulta comprensible sin su filosofía de la historia, sin esa confianza que aporta la esperanza en un futuro mejor, ${ }^{75}$ en el que necesariamente se ha de creer al modo de ineludible apuesta pascaliana. ${ }^{76}$ Por eso, quizá llevase razón Machado al suponer que:

[...] si alguien intentase algún día, para continuar consecuentemente a Kant, una cuarta Crtica, que sería la de la Pura creencia, llegaría en su Dialectica transcendental a descubrirnos acaso el carácter antinómico, no ya de la razón, sino de la fe, a revelarnos el gran problema del Sí y el No, como objetos, no de conocimiento, sino de creencia. ${ }^{77}$

\section{"La ley moral "tras" de mí y el cielo estrellado "ante"mi"s}

Lo cierto es que, con su filosofía de la historia, Kant esboza una serie de tesis que acaso podrían llegar a componer algo así como su Critica de la razón ucrónica. A mi modo de ver, en los textos donde alumbran esas tesis nuestro autor gusta de analizar la misma constelación de problemas explorada por la "Dialéctica» de su segunda Crítica. La solución kantiana para esa protoantinomia en la que nos hace reparar Machado, el dilema de creer, o no, en un devenir más o menos afortunado, en una marcha de las cosas mejor o peor dispuesta hacia nuestros proyectos, consiste - como sabemos - en mostrarse radicalmente pesimista con el pasado y rabiosamente optimista por cuanto atañe al futuro, ya que respecto a este último siempre nos cabe intentar esculpir su fisonomía con el cincel eidético de la razón práctica. También aquí se decreta un primado, que no es otro sino el de la razón elpidológica, cuyo interés soslaya de inmediato cualquier traba o escollo que a la experiencia pudiese antojársele como insuperable. Dicho primado nos habilita entonces para forjar dos postulados que posibiliten las demandas de nuestra razón elpidológica. Por una parte, se acuña la imagen de un decurso asintótico que se aproxima cada vez más al horizonte utópico configurado por el deber ser. De otro lado, se postula una ficción heurística que administre teleológica y eficazmente nuestra moralidad, allegándose así la condición necesaria para sustentar una plena confianza en el éxito de nuestros bienintencionados propósitos y albergar la íntima convicción de que nuestra libertad no conoce fronteras de ninguna especie gracias al pulso de la 
ética. Merced a estas premisas obtenemos una certeza de índole práctica que, si bien se revela insolvente para pronosticar el futuro con seguridad teórica, sí nos proporciona el aliento necesario para no desmayar en la persecución de nuestras metas prácticas, ni caer en la tentación de tomarlas por meras quimeras o vanas ilusiones. Sin ella, el formalismo ético kantiano queda inerte. $\mathrm{E}$ incluso ese modelo paradigmático de honestidad y rectitud, simbolizado por Spinoza en el $\$ 87$ de la Critica del Juicio, vería resquebrajarse su respeto hacia la ley moral en el caso de no apostar por tal esperanza.

La moral kantiana presenta, pues, un rostro jánico, en el que una de sus caras, de aire serio y circunspecto, como corresponde a su vertiente rigorista, convive con esa otra de semblante alegre y optimista, en cuyo lado moraría lo que aquí hemos dado en llamar el «imperativo elpidológico». Mientras la primera vuelve la vista hacia lo que se ha dejado atrás, para hacer balance a la hora del ocaso, la otra clava su mirada en el porvenir, escudriñando el despuntar del alba. Y es que, cuando la conciencia moral examina el pasado, es decir, lo que ya ha sido y no puede modificarse, no puede sino entristecerse y fruncir el ceño, imaginando cómo hubiera debido ser. Sin embargo, al encarar el futuro, su rostro se ilumina con la esperanza de que las cosas vayan a ser como debieran, dado que todo es posible todavía; nada nos impide proponernos arribar algún día hasta ese cielo estrellado que colma nuestro ánimo de admiración, desafiándonos a emprender viaje y surcar indefinidamente la galaxia de utopemas ucrónicos que nos acerca hasta él o, mejor dicho, no deja de incitarnos a "hacer camino" por el sendero de la ética, una senda cuyo horizonte se torna bien distinto según se trate del alba o del ocaso. De ahí su bifrontismo.

La gloria del ocaso cra un purpúreo espejo, era un cristal en llamas, que al infinito viejo va arrojando el grave soñar en la llanura... Y yo sentí la espuela sonora de mi paso repercutir lejana en cl sangricnto ocaso, y más allá, la alegre canción del alba pura.

\section{(Antonio Machado, Horizonte)}

\section{NOTAS}

1. Este artículo no sabrá dejar de rentabilizar, de una u otra manera, los diferentes trabajos que he venido publicando sobre la filosofia kantiana desde hace algunos años y que me propongo recopilar en un volumen bajo el título de Critica de la razón ucrónica (Estudios en tomo a las aporias morales de Kant), añadiendo un postfacio a guisa de introducción y confiando la tarea del prólogo a Javier Muguerza.

Inventariados por orden cronológico los mencionados artículos y estudios introducto- 
rios arrojan el siguiente saldo: $s \mathrm{El}$ bien supremo y sus postulados (Del formalismo ético a la fe racional)», Revista de Filasofía, 7 (1984), pp. 87-118; "El enfoque jurídico de la mendacidad según Kant", Agora, 5 (1985), pp. 247-253; "La filosofía kantiana de la historia. ¿Otra versión de la teología racional?", Revista de Filosofia, 6 (1985), pp. 21-40; "Postulado / hipótesis. Las dos facetas del dios kantiano», Pensamiento, 42 (1986), pp. 235-244; «La filosofia kantiana del derecho a la luz de sus relaciones con el formalismo ético y la filosofia crítica de la historia", Revista de Filosofía, 8 (1986), pp. 15-36; "La "revolución asintótica" de la metafísica kantianan, estudio prel. a I. Kant, Teoráa y práctica, Madrid, Tecnos, 1986, pp. X-XXIV; “La filosofía de la historia en Kant: una encrucijada de su pensamiento moral y político", en AA.V., Eticidad y Estado en el Idealismo alemán, Valencia, Natan, 1987, pp. 5-17; "El "utopismo ucrónico" de la reflexión kantiana sobre la historia», estudio prel. a I. Kant, Ideas para una historia universal en clave cosmopolita y otros escritos sobre filosofia de la historia. Madrid, Tecnos, 1987, pp. LX-XXXIX; "La presencia de la "Crítica de la razón práctica" en las "Lecciones de Ética" de Kant", Agora, 7 (1988), pp. 145-158; "La cara oculta del formalismo ético», estudio prel. a I. Kant, Lecciones de ética, Barcelona, Crítica, 1988, pp. 7-34; «El auténtico sujeto moral de la filosofía kantiana de la historia», en J. Muguerza y R. Rodriguez Aramayo (eds.), Kant después de Kant, Madrid, Tecnos, 1989, pp. 234-243; "Kant ante la razón pragmática (Una excursión por los bajos del deber ser)", estudio prel. a I. Kant, Antropologia práctica, Madrid, Tecnos, 1990, pp. IX-XXVI; "Un Kant fragmentario: la vertiente aforística del gran pensador sistemáticon, estudio prel. a mi Antologia de Kant, Barcelona, Península, 1991, pp. 7-21.

2. Cfr. Kr.V., A XVIII-XIX.

3. Cfr. Juan de Mairena (edición a cargo de José María Valverde), Madrid, Clásicos Castalia, 1978, p. 70.

4. $K r, V, B$ B 9

5. Ibid., A 602, B 630 .

6. "[...] las ideas de la razón no son productos arbitrarios y fantásticos, sino pensamientos que necesariamente se ocultan en todos los raciocinios que hacemos. Son como anticipaciones hipoteticas de fundamentos por descubrir, para que sirvan de apoyo a las realidades descubiertas. Nuestro conocimiento es siempre limitado y relativo. Si vamos preguntando el porqué de cada cosa, sin detenernos, llegaremos pronto al límite actual del saber. En ese límite se abre el mar insondable de lo ignoto; y la validez de lo conocido depende enteramente de los que nos queda aún por conocer. Pues bien, las ideas no son otra cosa sino expresión de la confianza que el espiritu humano tiene en que eso que es ignoto aún, está, sin embargo, regido por leyes firmes y seguras, que alguna vez podrán ser descubiertas. Esa confianza, esa seguridad, es la que nos da aliento para proseguir la obra de la investigación científica. Esta obra sería innecesaria si la metafísica pudiera realizar fielmente sus proycctos de conquista de lo absoluto. Pero csa conquista es, por definíción, irrealizable. Mas, por otra parte, la investigación cientifica sería un vano propósito si no estuviéramos convencidos de que tras los límites de nuestros actuales conocimientos hay lugar siempre para más conocimiento. Los problemas científicos son siempre problemas de limites, y las ideas de la razon no son sino garantias ciertas de que esos problemas de límites tienen de uno tt otro modo una solución posible" (Manuel García Morente, La filosofía de Kant, Madrid, Espasa-Calpe, 1975, pp. 130-131).

7. Ibid., A 235-236, B 294-295.

8. Cfr. Refl. 445; Ak., XV, 184.

9. Cfr. Padagogik, Ak., IX, 444.

10. CFr. Anthropologie in pragmatischer Hinsich, Ak., VII, 200.

11. CFr. Kr.V., A 317, B 374.

12. Cfr, K.r.V., A 318-319, B 375.

13. Ibid., A 316-317, B 373.

14. Cfr. Uber den Gemeinspruch..., Ak., VIII, 297 (cfr. I. Kant, Teoria y práctica, Madrid, Tecnos, 1986, p. 37). 
15. «Ninguna razón humana puede confiar en llegar a comprender la génesis de una simple hierbecilla por causas meramente mecánicas" (cfr. $K U ., A k, V, 409$ ); "la formación de todos los cuerpos siderales, la causa de sus movimientos, en fin, el origen de toda la constitución actual del universo, podrá ser comprendido con mayor facilidad que la génesis de una sola hierba, o la de una oruga, explicada exacta y completamente por meras causas mecánicas" (cfr. Allgemeine Naturgeschichte..., Ak., I, 230).

16. Ctr. Ak., XXIII, 75 (cfr. mi Antología de Kant, Barcelona, Península, 1991, p. 173).

17. Cfr. Idee.... Ak., VIII, 25 (I. Kant, Ideas para una historia universal en clave cosmopolita y otros escritos sobre fliosofia de la historia, Madrid. Tecnos, 1987, pp. 15-16).

18. Ibid., VIII, 18 (ibid., p. 5).

19. Cfr. Muthmaficher..., Ak., VII, 121 (ibid, p. 73).

20. Cfr. R.G. Collingwood, The Idea of History, Oxford, Clarendon Press, 1946, pp. 95-96. El subrayado es nuestro.

21. Cfr. ibid., p. 95.

22. "Newton advirtió por primera vez orden y regularidad alli donde antes no se hallaba sino caos y diversidad, dicumiendo desde entonces los cometas en trayectorias geométricas. Roursseau descubrió por primera vez bajo la diversidad de las configuraciones humanas adoptadas la naturaleza profundamente escondida del hombre y la ley oculta merced a la cual queda justificada la providencias (Ak., XXII, 58; fragmento 301 en mi Antología de Kant op. cit.).

23. Como es bien conocido, en la Critica del Juicio Kant califica de absurdo esperar el advenimiento de algún otro Newton que haga concebible aun tan sólo la producción de una simple brizna de hierba según leyes de la Naturaleza que no estén ordenadas por una intención" (K.U., Ak., V, 400).

24. Luckács, por ejemplo, le dedicará este comentario: "Kant no podía imaginar que medio siglo más tarde iba a nacer ese "Newton de la hierba": Darwin" (cfr. El joven Hegel [trad. de M. Sacristán], Barcelona, Grijalbo, 1976, p. 339)

25. Cfr. Idee..., Ak., VIII, 18 (cfr. Ideas..., op. cit., p. 5).

26. Cfr. K.p.V., Ak., V, 142.

27. Cfr. Ak., VMI, 65 (cfi. ldeas..., op. cit., p. 56).

28. Cfr. Emeuerte Frage..., Ak, VII, 92n. (cfr. ibtd, p. 97).

29. Cr. Refl. 1.396 (Ak., XV, 608; fragmento 160 en mi Antologla de Kant op. cit.).

30. Antropología de Friedländer, p. 674.

31. «U hombre puede sutilizar cuanto quiera para representarse una conducta de que ahora se acuerda, contraria a la ley, con los colores de un descuido sin intención, como mera imprevisión que no se puede evitar completamente, como algo, por tanto, en donde ha sido arrastrado por la corriente de la necesidad natural; puede tratar así de disculparse. Encuentra, sin embargo, que el abogado que habla en su favor no puede de ningún modo callar al acusador en él.... (K.p.V., Ak., V, 98).

32. Cfr. Muthmaßicher..., Ak., VIII, 121 (cfr. Ideas..., op. cit., p. 73).

33. Cfr, K.p.V., Ak., V, 99.

34. No nos es posible demostrar ninguna idea teórica o dotarla de realidad salvo en el caso de la idea de libertad, excepción que, ciertamente, obedece al hecho de configurar la condición de la ley moral, cuya realidad supone un axiomass (Refl. 2.842, Ak., XVI, 541; fragmento 283 en mi Antologia de Kant op. cit.).

35. Cfr. K. .V., A 317, B 374.

36. Cfr. Emenerte Frage..., Ak., VII, 80 (Ideas.., op. cit., p. 80).

37. Cfr. Idee..., Ak., VIII, 27 (cfr. ibid., pp. 17-18).

38. Cfr. Das Ende aller Dinge, Ak, VIII, 329-330.

39. Cfr. K.p.V., Ak., V, 130. Cfr. Ak., VIII, 278 (Teorta y práctica, op. cit., p. 10).

40. Refl. 1.418 (Ak., XV, 618; fragmento 162 en mi Antología de Kant op. cit.).

41. a cada miembro de la comunidad le ha de ser licito alcanzar dentro de ella una posición de cualquier nivel hasta el que pueda llevarde su talento, su aplicacion y su suerte. 
Y no es lícito que los cosúbditos le cierren el paso merced a una prerrogativa hereditaria* (cfr. Uber dem Gemeinspruch..., Ak, VII, 292; Teoria y prtictica, op. cit., p. 30).

42. Cfr. Idee..., Ak., VIII, 20 (cfr. Ideas..., op. cit., p. 8).

43. Cfr. K.r.V., A 805-6, B 833-4.

44. "Aquel que vive moralmente puede esperar ser recompensado por ello, si bien no debe dejarse motivar por esa esperanza" (cfr. Moralphilosophie Collins, Ak., XXVII, 1, 284) (cfr. I. Kant, Lecciones de ética, Barcelona, Crítica, 1988, p, 93). En Teorta y práctica se nos habla del bien supremo (el objeto elpidológico por excelencia) como de auna exigencia de la voluntad desinteresada, que va más alla de la observancia de las leyes formales" y constituye uuna determinación de la voluntad de carácter muy peculiar» (cfr. Ak., VIII, 279n.; ed. cast. cit., p. 12n.).

45. «Si he actuado de manera que me haya hecho digno de la felicidad, entonces también puedo esperar disfrutar de ella; tal es el móvil de la moralidad (Moralphilosophie Collins, Ak. XXVII.1, 304; cfr. Lecciones de ética, op. cit., p. 119).

46. Cfr. Rel., Ak., VI, 101.

47. Cfr. Refl. 2.793 (Ak., XVI, 513; fragmento 281 en mi Antologia de Kant op, cit.).

48. Cfr. Logik, Ak, DX, 68n.

49. Cfr. ibid., Ak., $\mathrm{XX}, 72$.

50. Cfr. Moralphilosophie Collins, Ak, XXVII.1, 321 (Lecciones de ética, op. cit., p. 137).

51. En sus Lecciones sobre filosofia de la religion, Kant efectuaba estas matizaciones en torno a la concepción estoica del destino, con objeto de conjurar posibles malentendidos: «Se cometería una injusticia para con cllos [los estoicos] si se les achacara el haber sosteni-

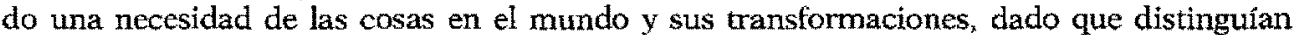
cuidadosamente entre fatum y necesidad, no entendiendo por fatum sino el gobierno y la providencia divinos» (Ak., XXVIII,2,2, 1.126).

52. Al referirse a lo que garantiza el advenimiento de la paz perpetua, Kant escribe lo siguiente: "Quien suministra este aval es nada menos que la naturaleza, en cuyo curso mecánico brilla visiblemente una finalidad, la de que a través del antagonismo de los hombres surja la armonía, incluso contra su voluntad; y por eso se le llama indistintamente destino, en cuanto causa necesaria de los efectos producidos conforme a leyes desconocidas para nosotros, o bien providencia, en atención a su finalidad en el curso del mundo, como recóndita sabiduría de una causa más elevada que apunta hacia el fin final del género humano y que predetermina ese curso del mundon (Ak., VIII, 360-361).

53. Cfr. Träume..., Ak., II, 349-350.

54. Cfr. Refl. 8.104, Ak, XLX, 646 (fragmento 157 en mi Antología de Kant op. cit.).

55. Cfr. Refl. 5.540, Ak., XVIII, 212 (fragmento 209 en mi Antologia de Kant op. cit.).

56. Cfr. Ak., XXI, 145.

57. En la Antropología se tilda de tautológica Ia divisa del uquerer es poder» con este razonamiento: ken efecto, lo que uno quiere por mandato de la propia razón moral imperati$v a$, debe hacerlo y, consiguientemente, también puede hacerlo (pues la razón no mandará nunca lo imposible) w (cfr. Ak., VI, 148).

58. «[...] cuya realidad, como una especie particular de causalidad (cuyo concepto sería transcendente en el sentido teórico), se deja exponer por leyes prácticas de la razón. pura y, conforme a ellas, en acciones reales; por tanto, en la experiencia. Es la única idea, entre todas las de la razón, cuyo objeto es un hecho y debe ser contado entre los scibilia» (K.U., Ak., V, 457).

59. «Desde luego, todo hombre se encuentra en su razón con la idea del deber y se estremece al escuchar su voz inflexible en cuanto se hacen sentir las inclinaciones que le tientan a desobedecerla. Se halla convencido de que, aun cuando éstas últímas se coaliguen para conspirar contra aquélla, la majestad de la ley que le prescribe su propia razón las dominará sin vacilar, saliendo así fortalecida su voluntad. ¿Qué es eso que hay en mí, capaz de hacer que pueda sacrificar los más sugestivos reclamos de mis instintos, así como todo deseo que tenga su origen en mi naturaleza, en aras de una ley que no me promete 
ningún beneficio y cuya transgresión no entraña perjuicio alguno? Esta pregunta embarga el ánimo de admiración hacia la grandeza y sublimidad de la disposición interna alojada en la humanidad, así como hacia la impenetrabilidad del enigma que la recubre (pues respon. der: "se trata de la libertad", sería caer en una tautología, dado que ésta representa el misterio mismo)" (cfr. Von einem neuerdings erhobenen vorrehmen Ton in der Philosophie, Ak., VIII, 402-403). Conviene recordar que, si bien la libertad constituye la ratio essendi de la ley moral, esta no deja de ser la ratio cognoscendi de aquélla (cfr. $K$ p.V., Ak., V, 4).

60 . «[...] y reconoce dentro de sí la libertad que, sin la ley moral, hubiese permanecido desconocida para él" (K.p.V., Ak., V, 30; cfr. Ak., V, 96 y 159).

61. Cfr. Uber den Gemeinspruch..., Ak., VIII, 287 (Teoria y practica, op. cit. p. 23).

62. Cfr. Ak., VII, 309-310 (ibid., p. 55).

63. Cfr. W.H. Walsh, Introducción a la filosofia de ia historia, Madrid, S. XXI, 1978, p. 147.

64. Cfr. O. Reboul, Kant et le problème du mal, Les Presses de l'Université de Montréal, 1971, p. 216. p. 539.

65. Cfr. L. Landgrebe, «Die Geschichte in Denken Kants», Studium Generale, 7 (1954),

66. L. Goldmann, cuando menos, sostiene que «dentro de la filosofia kantiana de la religión estaba ya contenida, como consecuencia natural e inevitable, la religión inmanente de una comunidad humana superior y autentica: el pensamiento socialista" (cfr. Introduccion a la filosofía de Kant, Buenos Aires, Amorrortu, 1974, p. 202).

67. Problèmes Kantiens, París, J. Vrin, 1970, p. 115.

68. Cfr. El hombre y to absoluto (trad. de Juan Ramón Capella), Barcelona, Península, 1968 , p. 398.

69. Ctr, Das Ende aller Dinge, Ak, VII, 337.

70. Cfr. Rel., Ak, V, 4.

71. Rel., Ak., VI, $7 \mathrm{n}$.

72. Así se resuelve la pseudoparadoja que apuntábamos más aniba y sobre la que prometíamos retomar. El deber es condición de toda esperanza legítima, pero esta es la clave de acceso al mismo.

73. Cfr., v.g., K.p.V., Ak., V, 109-110, y Rel., Ak., VI, 6 n.

74. Cfr. Uber den Gemeinspruch..., Ak., VIII, 309 (Teoria y práctica, op. cit. p. 54),

75. «Ante el triste espectáculo que ofrecen, no tanto los males que agobian al género humano por causas naturales, sino más bien aquellos que los propios hombres se infligen mutuamente, el ánimo se reconforta gracias a la perspectiva de que el futuro puede ser mejor» (Ak., VIII, 309; p. 55).

76. En caso contrario nos encontraríamos con ese hombre recto, ejemplificado por Spinoza, del que nos habla el $\$ 87$ de la tercera Critica. Éste, pese a tener decidido ejercer la ley moral sin abrigar ninguna mira interesada ni en base a provecho propio alguno, se verá rodeado por el engaño, la violencia y la envidia, afligiéndose además por la suerte de otros hombres justos que se hallan sumidos en la miseria o atenazados por las enfermedades más crueles; por ello, a fin de uno debilitar el respeto que la ley moral le inspira inmediatamente", habrá de acabar por admitir que su buen obrar pueda resultar administrado por algo distinto a la casualidad, al ciego azar, y creer que con su moralidad puede llegar a modificar el orden actual de las cosas, convicción perfectamente asumible, dado que, cuando menos, no es contradictoria en sí misma (cfr. K.U., Ak., V, 452-453); es decir, que debe apostar por la esperanza, para no caer en la desesperación.

77. Cfr. Juan de Mairena, op. cit., p. 271. 